\title{
Cup-Shaped Tooth Wear Defects: More than Erosive Challenges?
}

\author{
Jan L. Ruben ${ }^{a} \quad$ F. Joost M. Roeters ${ }^{b}$ Gert-Jan Truin ${ }^{a}$ Bas A.C. Loomans ${ }^{a}$ \\ Marie-Charlotte D.N.J.M. Huysmans ${ }^{\text {a }}$ \\ a Department of Dentistry, Radboud University Medical Center, Radboud Institute for Health Sciences, Nijmegen, \\ The Netherlands; ${ }^{b}$ Department of Dental Materials, Academic Center for Dentistry (ACTA), Amsterdam, The \\ Netherlands
}

\section{Keywords}

Tooth wear · Tooth abrasion - Tooth erosion · Profilometry · Bite force

\begin{abstract}
Background/Aim: The underlying mechanism of the development of cups and grooves on occlusal tooth surfaces is still unclear. The aim of this study was to evaluate factors contributing to in vitro cup formation, in order to elucidate the clinical process. Methods: A total of 48 extracted human molar teeth were exposed to acidic aqueous solutions at $\mathrm{pH}$ of 4.8 and 5.5 in constant motion, in combination with different loading conditions: no load (0N group, control), $30 \mathrm{~N}$ ( $30 \mathrm{~N}$ group) or $50 \mathrm{~N}$ ( $50 \mathrm{~N}$ group) ( $n=8$ per group). Before and after 3 months of exposure (1,422,000 loading cycles), the samples were scanned using a non-contact profilometer. Pre- and post-exposure scans were subtracted and height loss and volume tissue loss were calculated. Representative samples with wear and cupping lesions were imaged using scanning electron microscopy, light microscopy and microcomputed tomography. Results: Average height and volume tissue loss at pH 5.5 was $54 \mu \mathrm{m}$ and $3.4 \mathrm{~mm}^{3}(0 \mathrm{~N}), 52 \mu \mathrm{m}$ and $3.4 \mathrm{~mm}^{3}(30 \mathrm{~N})$ and $58 \mu \mathrm{m}$ and $3.7 \mathrm{~mm}^{3}(50 \mathrm{~N})$, respec-
\end{abstract}

tively, with no statistically significant differences. Average height and volume loss at $\mathrm{pH} 4.8$ were $135 \mu \mathrm{m}$ and $8.7 \mathrm{~mm}^{3}$ (ON), $172 \mu \mathrm{m}$ and $12.6 \mathrm{~mm}^{3}(30 \mathrm{~N})$ and $266 \mu \mathrm{m}$ and $17.8 \mathrm{~mm}^{3}$ $(50 \mathrm{~N})$, respectively, with a statistically significant difference between $0 \mathrm{~N}$ and $50 \mathrm{~N}(p<0.002)$. Cup-shaped lesions had formed only at $\mathrm{pH}$ of 4.8 , in the $30 \mathrm{~N}$ and $50 \mathrm{~N}$ groups. Conclusion: The study showed that a cup can arise fully in enamel and that mechanical loading in addition to erosive challenges are required.

(c) 2019 The Author(s)

Published by S. Karger AG, Basel

\section{Introduction}

Erosive tooth wear has been described as a multi-factorial condition involving chemical and mechanical factors. The chemical factor in this process is called erosion, and involves the dissolution of tooth tissues due to acids from a non-microbiological origin. The source of these acids can be extrinsic (such as dietary acids) or intrinsic (gastric regurgitation or vomiting) [Jarvinen et al., 1991]. The mechanical factors in wear are related to friction by tooth-tooth contact (attrition) or interaction with other objects or substances, for instance nail biting, tooth 
brushing or mastication (abrasion). Although each of these processes may produce wear, the aetiology will be multifactorial in most cases. A strong interaction is the potentiating of attrition and abrasion by erosive damage to the dental hard tissue [Shellis et al., 2014].

Characteristic clinical features of erosive wear are smooth silky-glazed appearance of the enamel and disappearance of perikymata and intact enamel present along the gingival margin, with a local defect described as cupping, grooving or cratering on occlusal surfaces [Khan et al., 2001; Lussi et al., 2006; Ganss and Lussi, 2014]. The cupping/grooving feature is often described as pathognomonic for erosive wear [Verrett, 2001], but there is some debate about the mechanisms leading to cupping or grooving.

According to one author "cups" and "grooves" form by accelerated wear of the softer dentine after enamel is worn away [Mair, 1992]. These cups or grooves must result from abrasion and/or chemical action since there is no direct contact with the opposing tooth surface at the base of the defect. Whereas some believe that abrasion is the most important factor [Abrahamsen, 2005], others stress the role of erosion [Mair, 1992]. It has been described as the combined effect of demineralization of the tooth surface by an erosive agent and abrasion of the demineralized surface by surrounding oral soft tissues, food mastication and tooth brushing [Ganss et al., 2006]. Clinically, it is very difficult to differentiate between the specific effect of both factors [Ganss et al., 2014]. In our own dental clinic we have observed what appeared to be early cupping lesions, limited to the enamel, and this has also been reported in the literature [Johansson et al., 2012]. As this cannot be explained by the differential wear of enamel and dentine, an alternative/additional theory must be proposed.

It was the aim of this study to evaluate in vitro the effects of different erosive and mechanical challenges on the occlusal wear of molar teeth, with a specific aim of creating cupping lesions, and to determine whether cupping lesions may develop within the enamel.

\section{Materials and Methods}

Extracted sound human lower third molars were selected, cleaned and stored in water. Teeth were embedded in acrylic resin (Autoplast cold curing denture base material; Candulor, Wangen Switzerland). Forty-eight specimens were prepared and subsequently assigned randomly to one of six groups $(n=8)$, exposed to one of two different acidity levels of $\mathrm{pH} 4.8$ and $\mathrm{pH} 5.5$, and one of three different loading protocols: no loading ( $0 \mathrm{~N}$ group, control) or mechanical loading with a force of 30 or $50 \mathrm{~N}(30 \mathrm{~N}$ and $50 \mathrm{~N}$ groups).
Specimens were mounted into the Rub\&Roll [Ruben et al., 2014, 2018], device for 3 months in a demineralization solution which filled the outer cylinder, containing $0.1 \mathrm{M}$ lactic acid, $1.5 \mathrm{mM} \mathrm{CaCl}_{2}$, $0.9 \mathrm{mM} \mathrm{KH}_{2} \mathrm{PO}_{4}, 10 \mathrm{~mL}$ chloramine $1 \%, 0.5 \mathrm{ppm} \mathrm{F}$ in demineralized water and titrated with $10 \mathrm{M} \mathrm{KOH}$, respectively, to the $\mathrm{pH} 4.8$ and $\mathrm{pH}$ 5.5. The $\mathrm{pH}$ of the solution was checked every day and the liquid was changed twice a week or at a maximal increase of $\mathrm{pH}$ of 0.2 . Mechanically loaded specimens were loaded at $20 \mathrm{rpm}, 0.4 \mathrm{~Hz}$, resulting in 1,422,000 loading movements simulating chewing strokes, applied in the axial direction. Control groups were not loaded, but were immersed and rotated in the demineralizing solutions.

\section{Measurements}

Before and after 3 months of exposure, specimens were unmounted and optical non-contact 3D surface measurements were performed (Proscan 2100; Scantron, Taunton, UK) with a confocal sensor S29/10-10,000 $\mu \mathrm{m}$. The step size was set at $0.04 \mathrm{~mm}$ and the number of steps at 375 in the (X) axle; and 300, respectively, in the (Y) axle, leading to a total scan surface area of $15 \times 12 \mathrm{~mm}$. With the use of dedicated software (Proform; Scantron), subtraction of before and after scans was performed and the mean height loss $(\mu \mathrm{m})$ and volume loss $\left(\mathrm{mm}^{3}\right)$ were calculated based on the subtraction of the average height of the molars without loading from the average height of the loaded molars. The average height difference and mean volume difference of 8 specimens of each group after 3 months were calculated.

\section{Statistical Analysis}

The data were statistically checked for normal distribution by Shapiro-Wilk tests. Once this condition was met, one-way ANOVA with post hoc Tukey tests were carried out for comparisons among groups. The software IBM SPSS Statistics (released 2013) (IBM SPSS Statistics for Windows, Version 22; IBM Corp., Armonk, NY, USA) was used for the calculations. The significance level was set at $p<0.05$.

\section{Scanning Electron Microscopy}

One sample from each group was prepared for scanning electron microscopy (SEM). The action of loading produced a smear layer on the top surface, mainly composed of grinding debris containing small microcrystalline and organic particles. In order to examine the possible damaged top surface of the affected occlusal surfaces with SEM, the smear layer was removed carefully using $\mathrm{NaOCl}$ [Wang et al., 2017]. The specimens were exposed to a $2.5 \%$ $\mathrm{NaOCl}$ solution for 3 min during constant agitation with a brush. The specimens were air-dried and mounted on a single stub, sputter-coated with gold in a high-vacuum evaporator and analysed under a scanning electron microscope (Zeiss Sigma 300 Field Emission Scanning Electron Microscope), with $50 \times, 2,000 \times$ and $10,000 \times$ magnification on the occlusal/transversal affected area.

\section{Light Microscopy}

One sample from each group was selected for light microscopy. From each tooth, a section was cut with a diamond saw from the central part of the lesion and a ground section was prepared for polarized light microscopy. Specimens were photographed using a polarized light microscope (Leica M50 stereomicroscope equipped with a Canon EOS1 digital camera) to evaluate the morphology of the demineralized surface on the enamel samples [de Medeiros et al., 2012]. 


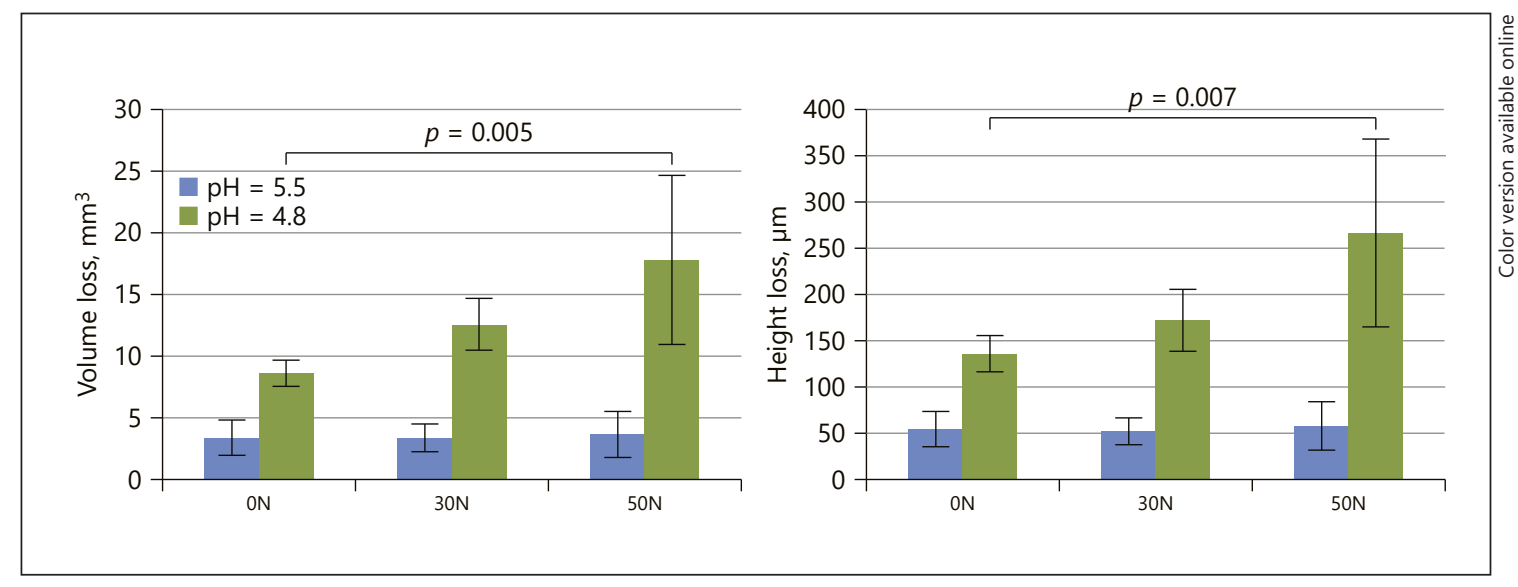

Fig. 1. Mean volume loss $\left(\mathrm{mm}^{3}\right)$ and height loss $(\mu \mathrm{m})$ for all groups. Standard deviations are indicated by whiskers. Statistical differences between groups are indicated.

Micro-Computed Tomography

One sample from the group with acidity level of 4.8 and loading protocol $50 \mathrm{~N}$ was selected. The sample was scanned at $2.7 \mu \mathrm{m}$ isotropic voxel size (Phoenix NanoTom S; GE Measurement and Control Solutions, Billerica, MA, USA). The source, equipped with a tungsten target, was operated at $90 \mathrm{kV}$ and $110 \mu \mathrm{A}$. No filter was used. Because the "fast mode" settings (i.e., exposure time $500 \mathrm{~ms}$, frame averaging 1 and skip 0 ) were used, the scanning time was only $20 \mathrm{~min}$. The image was visualized in $3 \mathrm{D}$ using the volume rendering program CTV ox (Bruker MicroCT, Kontich, Belgium). Hereby, a clipping tool was applied to produce the cut-away view, and an interactive transfer function to adjust colour and transparency.

\section{Results}

The mean height loss and mean volume tissue loss for each group after 3 months of exposure are presented in Figure 1. No statistical differences between mean height ( $p=0.926)$ and volume $(p=0.843)$ loss were found between the groups exposed at $\mathrm{pH} 5.5$. At $\mathrm{pH} 4.8$, the $50 \mathrm{~N}$ group resulted in a statistically significant increase in height loss $(266 \pm 101 \mu \mathrm{m})$ and volume loss $(17.8 \pm 6.83$ $\mathrm{mm}^{3}$ ) compared to the $0 \mathrm{~N}$ control group, showing a height of $135 \pm 19 \mu \mathrm{m}$ and volume loss of $8.7 \pm 1.0 \mathrm{~mm}^{3}$ $(p<0.002)$. No statistically significant effect was found for the $30 \mathrm{~N}$ group compared to the control group (height $p=0.791$, volume $p=0.496$ ).

Cup-shaped lesions could be seen to have formed at a pH of 4.8 (Fig. 2, 3) in the $30 \mathrm{~N}$ and $50 \mathrm{~N}$ groups. In the control group, even at $\mathrm{pH} 4.8$, minimal tissue loss was observed on the cusps (Fig. $2-0 \mathrm{~N}$ ). Different features/ regions could be recognized in the higher-loaded specimens. The cup-shaped lesions are characterized by multiple cavities and partly overlapping grooves, where on the surface a terrace structure can be observed with indented layering, as well as (micro)fractures and structural loss. (Fig. 3 - overview). The enamel on the edge of the cup was slightly polished (Fig. 3A, E) and "polished" key-hole structures (Fig. 3F) can be seen as a sign of erosive wear of the enamel. Separation of enamel prisms was observed directly behind the cup edge (Fig. 3B). In the middle part (deepest area) of the cup the material loss is more pronounced. The damaged prisms are eroded/abraded and compressed, and a smear layer seems to arise (Fig. 3C, D, G). A more pronounced smear layer is visible in the $50 \mathrm{~N}$ specimen (Fig. $3 \mathrm{H}, \mathrm{I}$ ). In addition, in the $50 \mathrm{~N}$ specimen the cup formation in both the depth and the surface was more pronounced than in the $30 \mathrm{~N}$ specimen, with multiple cups extending into the dentine (Fig. 3I).

Transmitted and polarized light microscopy of a $100-\mu \mathrm{m}$ section from a sample from the $\mathrm{pH} 4.8 / 50 \mathrm{~N}$ group showed outer demineralization (Fig. 4, parts 2, 3 ). The demineralized layer can be observed to be thinner at the bottom of the cup-shaped defect. Figure 5 shows a micro-computed tomography $(\mu \mathrm{CT})$ section image of a similar specimen. Again, the demineralized layer may be observed at the surface, with this layer appearing thinner or worn away in the cup-shaped lesion. The mineral density underneath the loaded part of the cusps is lowered; locally, the enamel appears to be damaged. 


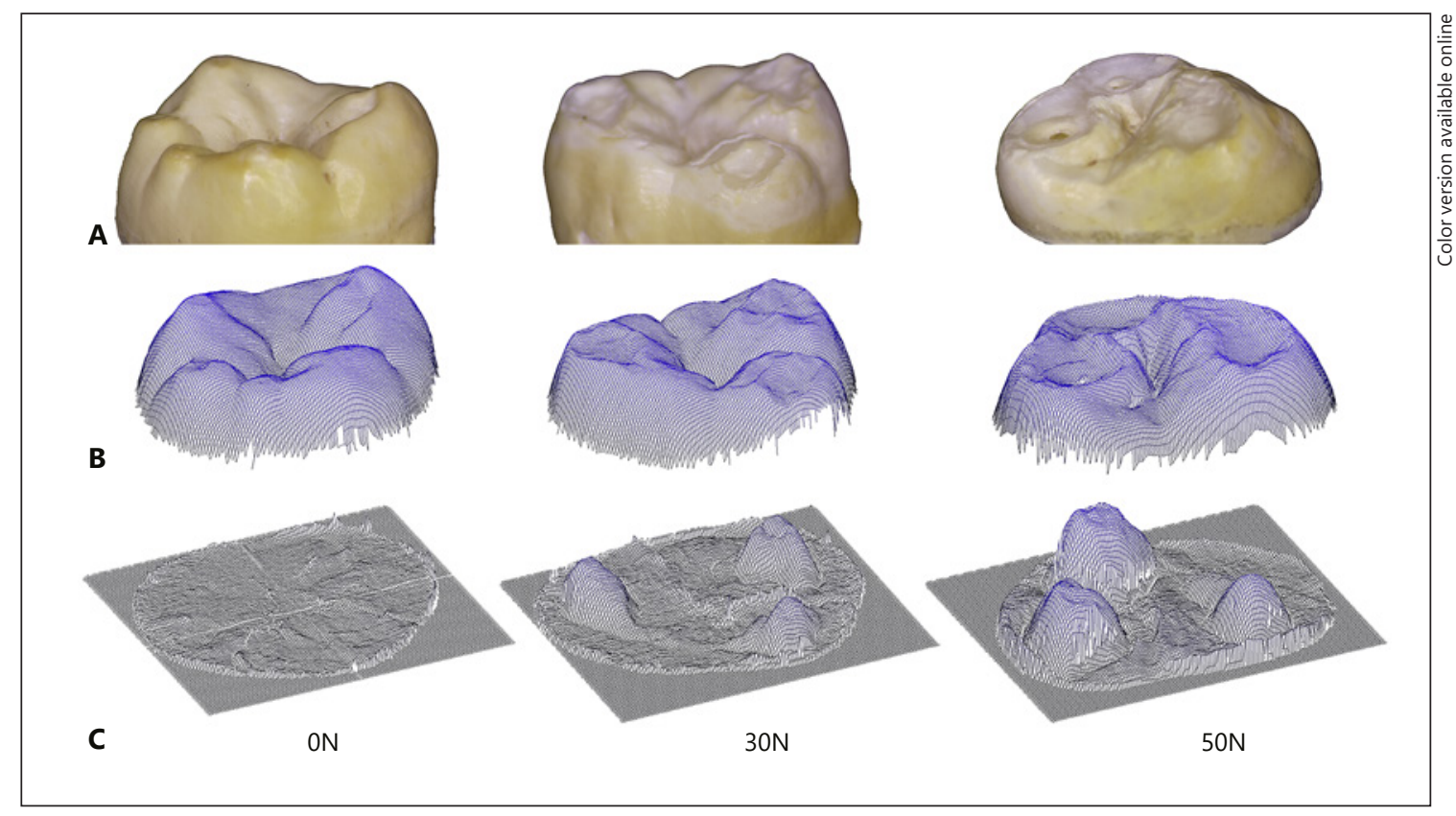

Fig. 2. Images of a representative specimen from each loading group exposed to $\mathrm{pH}$ 4.8. A Stereomicroscopic image. B Non-contact profilometer scan. C Subtraction result. Minimal wear of the cusps can be observed at 0N, with cup-shaped lesions visible in the $30 \mathrm{~N}$ and more distinctly in the $50 \mathrm{~N}$ group. In the stereomicroscopic view of the $50 \mathrm{~N}$ sample exposure of dentine at the bottom of one cup-shaped lesion can be observed.

\section{Discussion}

The aim of this study was to investigate the specific circumstances which allow for the development of cupshaped lesions, and to confirm their development already within the enamel. In the present set-up both the mechanical and the chemical exposure could be varied and controlled [Ruben et al., 2014, 2018]. Cup-shaped erosive wear lesions developed in an erosive liquid with a $\mathrm{pH}$ value of 4.8 combined with a simulated chewing force of either 30 or $50 \mathrm{~N}$.

In this in vitro study, the teeth were exposed for 3 months in a permanently acidic environment, which is different from the clinical conditions. The chewing load, however, was placed on the cusps with a clinical equivalent pressure and speed. The cup-shaped lesions always started in the surface enamel on the slope of the cusps. In the clinical setting, the periods of an erosive environment will be limited and alternated with periods of (super)saturation, which will slow down the formation of the cup. Typically, such defects take years to develop in a clinical situation. In a pilot study (unpubl. data), an erosive medium with a $\mathrm{pH}$ value lower than 4.6 only produced erosive wear, with facets on cusp tips without cupping. Only very little wear and no cup-shaped enamel defects developed at a $\mathrm{pH}$ of 5.5. In order to form a cup-shaped lesion, a balance must be formed between the mechanical force and an acidic environment, which must be slightly lower than the critical $\mathrm{pH}$ value (generally accepted to be about 5.5) of the enamel surface which is subjected. The critical $\mathrm{pH}$ of enamel is not constant. By increasing the concentration of calcium and/ or phosphate in the demineralization solution, it is possible to reduce the effective critical $\mathrm{pH}$ so that enamel is able to withstand lower $\mathrm{pH}$ values before demineralizing [Dawes 2003; Featherstone 2008]. In this study we used a saliva-like composition of the demineralization solution, so the usual critical $\mathrm{pH}$ as defined for caries is relevant here. The development of a cup appears to be a delicate process, in which the balance between erosion (demineralization) and abrasion appears to be crucial. At a $\mathrm{pH} \leq 4.6$ this balance seems to have been disrupted to develop cupping. When the $\mathrm{pH}$ is too low the enamel is softened and the solved components may exhibit a smearing action resulting in less friction [Eisenburger and Addy, 2002]. A higher $\mathrm{pH}$ may still erode the enamel, while there is enough frictional loading to damage the enamel by separating the enamel prisms. Separation of 


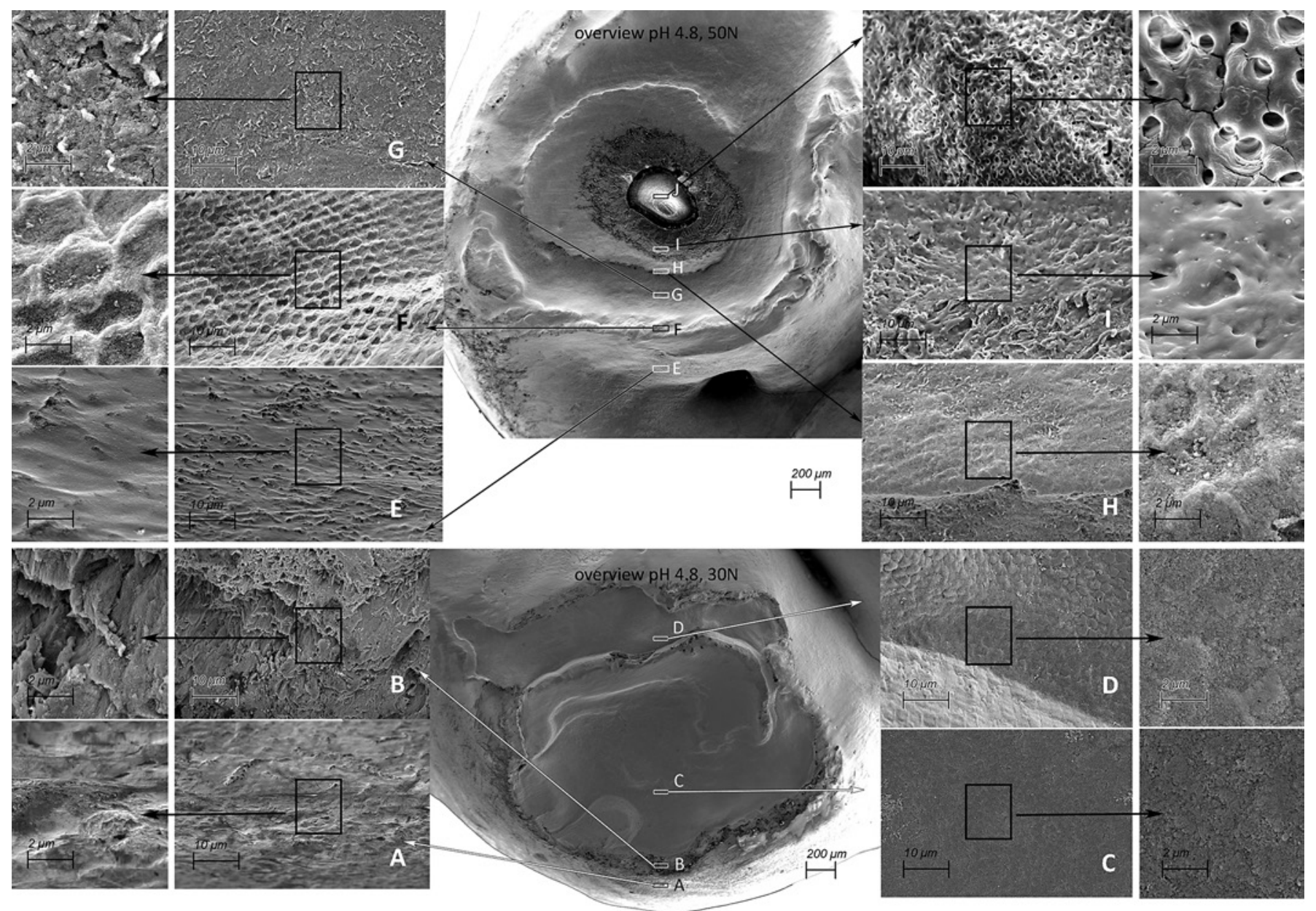

Fig. 3. SEM pictures of cup-shaped defects from a $50 \mathrm{~N}$ specimen exposed to $\mathrm{pH} 4.8$ (top, cup-shaped lesion extending into dentine) and a $30 \mathrm{~N}$ specimen exposed to $\mathrm{pH} 4.8$ (bottom, cup-shaped lesion limited to the enamel). Overview magnification, $\times 50$. The frames indicated A-J show enlargements of areas in the cup-shaped lesion. Magnification, $\times 2,000$ and $\times 5,000$. In the overview cup shape lesions can be observed by multiple cavities and partly overlapping grooves, where on the surface a terrace structure can be observed with indented layering. A, E The enamel on the top of the cusp is slightly polished, the enamel is softened, and the solved components may exhibit a smearing action resulting in less friction and damage. B Enamel prism separated from each other. Separation of prisms will facilitate a deep penetration of acid. F "Polished" keyhole structures can be seen. C, D, G The damaged prisms are eroded/abraded and compressed, and a smear layer seems to arise. $\mathbf{H , ~ I}$ In the lowest part of the formed cup-shaped lesion the surface is eroded/abraded and compressed, and a more pronounced smear layer is visible. $\mathbf{J}$ Exposed dentine. prisms will facilitate a deep penetration of the acid [Bajaj and Arola, 2009]. Due to the acid, enamel will dissolve and the interprismatic space will increase and finally loosen the prisms. The remaining prisms will be increasingly subjected to lateral forces. Such forces have a more disruptive effect than axial forces, presumably because the enamel prisms of the cusp are resistant to the growth of subsurface cracks along the axis of the enamel [Gao et al., 2016].

Enamel is the most highly mineralized tissue in the human body and has enamel prisms arranged in columnar fashion surrounded by a sheath of non-collagenous matrix - the prism sheath. The prism sheath contains a small percentage of protein that gives the enamel metal-like properties with an ability to sustain repetitive cyclic contact loading [He and Swain, 2007]. Enamel has anisotropic characteristics because of its prismatic structure, making enamel stiffer in the prism direction compared to the perpendicular direction. Both hardness and elastic modulus are high but vary within the location in the tooth $[\mathrm{Xu}$ et al., 1998]. Enamel owes its wear resistance also to its fracture toughness, which is the ability to withstand the 
Fig. 4. Stereomicroscopic images in the top row show a sound specimen (left) and after exposure (right) of a specimen from the $\mathrm{pH}$ $4.8 / 50 \mathrm{~N}$ group, with lines $\mathrm{A}$ and $\mathrm{B}$ indicating the location of the $100-\mu \mathrm{m}$ sections imaged below. Sections assessed by transmitted light microscopy (2A, 2B) and polarized light (3A, 3B): (a) indicates the outline of the original shape of the cusps, (b) the demineralized top surface, and (c) the "deepest" point of the cup-shaped lesion at the location of the dentine "cusp" tip.
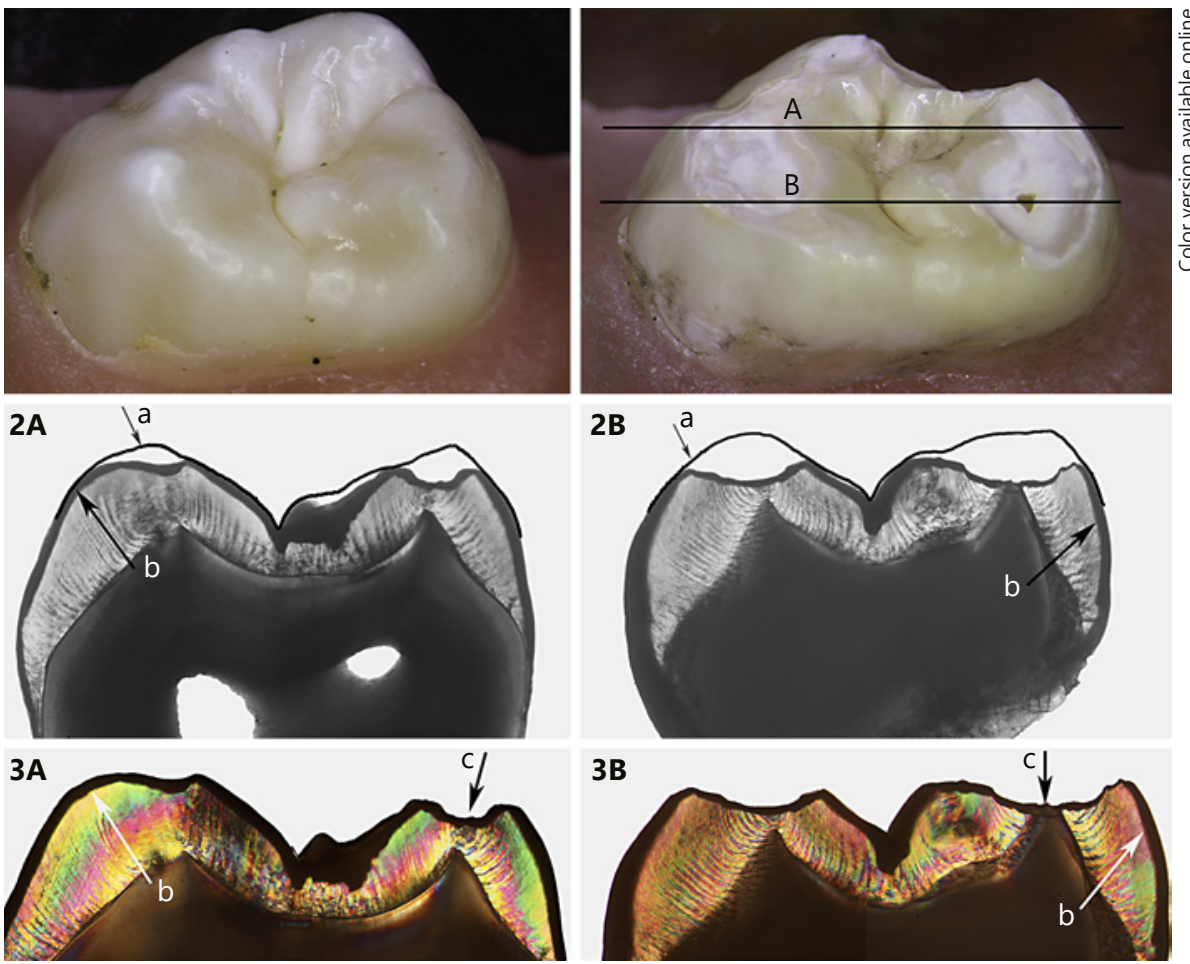

growth of cracks. Interwoven networks or prism bundles in enamel increase the resistance to fracture, known as decussating. The crack growth resistance is a function of distance from the tooth's surface, where straight prisms are present in the outer enamel and oblique crossing of bundles of prisms (decussating) in the inner enamel [Bajaj and Arola, 2009]. According to Lucas and van Casteren [2015], cracks (fractures) can be initiated when sufficient strain energy is available. A large and hard particle under the contact area can produce a fracture in the underlying enamel just above the enamel dentine junction, although a smaller and softer particle can also cause fractures due to bending deformation further from the contact area.

The load in this study was applied in the axial direction in a rolling (not sliding) motion. The antagonist used in this study is a metal inner tube inserted in a PVC hose mimicking a tough food bolus. Cup formation is clearly load-dependent, with higher loads leading to deeper cupshaped defects at the same solution $\mathrm{pH}$ (Fig. 3J). Although the exact behaviour of the liquid, being squeezed out between the tooth surface and the loading tube, and the deformation of the loading tube's PVC coating may not be clear, it can be observed that the combination of these forces in an acidic environment produces a combination of

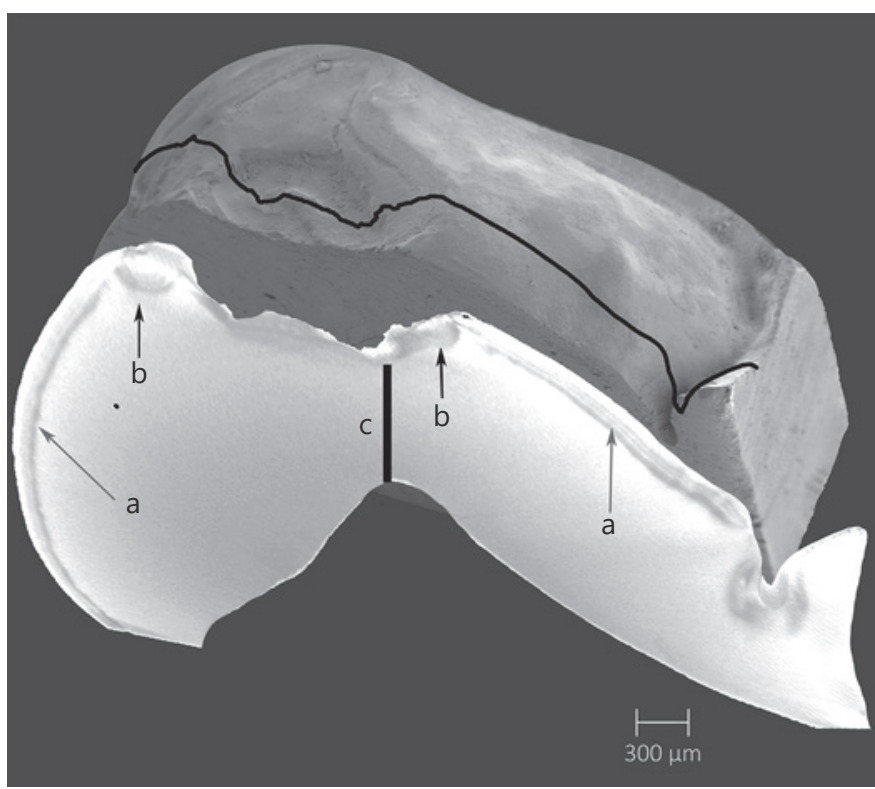

Fig. 5. Representative specimen from the $\mathrm{pH} 4.8 / 50 \mathrm{~N}$ group. Top view is an SEM image (magnification, $\times 50$ ) and underneath a $\mu \mathrm{CT}$ image slice at the cross-section indicated by the line: (a) indicates surface demineralization, (b) damaged enamel near the cusp tip, and (c) the remaining enamel between the bottom of the cupshaped lesion and the dentine "cusp" tip. 
crushing damage and wear, as seen by the different areas in the SEM with lamination (Fig. 3B) and polishing (Fig. 3D).

The effect of mechanical loading in the presence of an erosion medium will ensure that the acidic medium can more easily diffuse (penetrate) into the enamel surface. This process can result in a loosening and complete dislodgement of enamel prisms. At this time, increasing lateral forces (form of the bolus or the fluid flow) will occur on the damaged enamel, resulting in widening of the cup and roughening of the surrounding enamel. Cracks arising at the enamel surface and propagating inwards may be diverted by decussation, back towards the surface. The resulting shape of the fracture may vary according to the force direction. On the side where the mechanical load enters the defect (depending on chewing in the stroke direction, and on the Rub\&Roll in the rotational direction and tooth orientation), the enamel prisms are pushed in the direction of the cup, where they are unsupported, resulting in a faster release. At the opposite "exit side" of the cup, the enamel prisms are loaded into compression and pressed against sound enamel. The "deepest" extension of the cup-shaped lesion appears to be at the location of the original cusp tip, progressing in the direction of the corresponding dentine protrusion.

\section{Conclusion}

The configuration of acidic (below the critical pH of enamel) and mechanical loading challenges resulted in the formation of cup-shaped defects on occlusal permanent molar surfaces in vitro. The present study showed that a cup can arise fully in enamel and the dentine does not always need to be exposed first, thus dismissing the causation theory of preferential wear of dentine.

\section{Acknowledgements}

The authors wish to thank Dr. V. Cuijpers, Department of Biomaterials of the Radboud University, for performing and interpreting the $\mu \mathrm{CT}$ measurements. The $\mu \mathrm{CT}$ images were generated on the X-ray CT facility of the Department of Development and Regeneration of the KU Leuven Belgium, financed by the Hercules Foundation.

\section{Statement of Ethics}

The authors have no ethical conflicts to disclose. As extracted teeth were anonymously collected an ethics committee approval was not required in The Netherlands.

\section{Disclosure Statement}

The authors have no conflicts of interest to declare. They received no funding relevant to this study.

\section{Author Contributions}

J.L. Ruben, F.J.M. Roeters and G.-J. Truin contributed equally to the design, data acquisition and interpretation, drafting and critically revising the manuscript. B.A.C. Loomans and M.C.D.N.J.M. Huysmans contributed equally to drafting and critically revising the manuscript. All authors gave final approval and agree to be accountable for all aspects of the work.

\section{References}

Abrahamsen TC. The worn dentition-pathognomonic patterns of abrasion and erosion. Int Dent J. 2005;55(4 Suppl 1):268-76.

Bajaj D, Arola DD. On the R-curve behavior of human tooth enamel. Biomaterials. 2009 Aug; 30(23-24):4037-46.

Dawes C. What is the critical $\mathrm{pH}$ and why does a tooth dissolve in acid? J Can Dent Assoc. 2003 Dec;69(11):722-4.

De Medeiros RC, Soares JD, De Sousa FB. Natural enamel caries in polarized light microscopy: differences in histopathological features derived from a qualitative versus a quantitative approach to interpret enamel birefringence. J Microsc. 2012 May;246(2):177-89.
Eisenburger M, Addy M. Erosion and attrition of human enamel in vitro part I: interaction effects. J Dent. 2002 Sep-Nov;30(7-8):341-7.

Featherstone JD. Dental caries: a dynamic disease process. Aust Dent J. 2008 Sep;53(3):286-91.

Ganss C, Klimek J, Lussi A. Accuracy and consistency of the visual diagnosis of exposed dentine on worn occlusal/incisal surfaces. Caries Res. 2006;40(3):208-12.

Ganss C, Lussi A. Diagnosis of erosive tooth wear. Monogr Oral Sci. 2014;25:22-31.

Ganss C, Lussi A, Schlueter N. The histological features and physical properties of eroded dental hard tissues. Monogr Oral Sci. 2014;25: 99-107.
Gao SS, An BB, Yahyazadehfar M, Zhang D, Arola DD. Contact fatigue of human enamel: Experiments, mechanisms and modeling. J Mech Behav Biomed Mater. 2016 Jul;60:43850.

He LH, Swain MV. Enamel - a "metallic-like" deformable biocomposite. J Dent. 2007 May; 35(5):431-7.

Järvinen VK, Rytömaa II, Heinonen OP. Risk factors in dental erosion. J Dent Res. 1991 Jun; 70(6): $942-7$.

Johansson AK, Omar R, Carlsson GE, Johansson A. Dental erosion and its growing importance in clinical practice: from past to present. Int J Dent. 2012;2012:632907. 
Khan F, Young WG, Law V, Priest J, Daley TJ. Cupped lesions of early onset dental erosion in young southeast Queensland adults. Aust Dent J. 2001 Jun;46(2):100-7.

Lucas PW, van Casteren A. The Wear and Tear of Teeth. Med Princ Pract. 2015;24(suppl 1):3-13.

Lussi A, Hellwig E, Zero D, Jaeggi T. Erosive tooth wear: diagnosis, risk factors and prevention. Am J Dent. 2006 Dec;19(6):319-25.

Mair LH. Wear in dentistry-current terminology. J Dent. 1992 Jun;20(3):140-4.
Ruben JL, Roeters FJ, Montagner AF, Huysmans MC. A multifunctional device to simulate oral ageing: the "Rub\&Roll". J Mech Behav Biomed Mater. 2014 Feb;30:75-82.

Ruben JL, Truin GJ, Loomans BAC, Huysmans MDNJM: Mimicking and Measuring Occlusal Erosive Tooth Wear with the "Rub\&Roll" and Non-contact Profilometry. J Vis Exp. 2018 Feb;132:e56400.

Shellis RP, Featherstone JD, Lussi A. Understanding the chemistry of dental erosion. Monogr Oral Sci. 2014;25:163-79.

Verrett RG. Analyzing the etiology of an extremely worn dentition. J Prosthodont. $2001 \mathrm{Dec}$ 10(4):224-33.
Wang TF, Feng XW, Gao YX, Wang M, Wang YN, Sa Y, et al. Effects of different concentrations and exposure time of sodium hypochlorite on the structural, compositional and mechanical properties of human dentin. J Huazhong Univ Sci Technolog Med Sci. 2017 Aug;37(4):568-76.

Xu HH, Smith DT, Jahanmir S, Romberg E, Kelly JR, Thompson VP, et al. Indentation damage and mechanical properties of human enamel and dentin. J Dent Res. 1998 Mar;77(3):472-80. 